\title{
Group-Based Motivational Interviewing for Alcohol Use Among College Students: An Exploratory Study
}

\author{
Kurt D. Michael, Lisa Curtin, Dale E. Kirkley, and \\ Dan L. Jones \\ Rafael Harris Jr. \\ Appalachian State University \\ University of Florida

\begin{abstract}
How can practicing psychologists help reduce excessive alcohol consumption among college students? Over $80 \%$ of college students consume alcohol, and a significant percentage drinks excessively with myriad problems. Brief interventions based on motivational interviewing (MI) have been identified for use with college populations. The authors randomly assigned 91 freshman students to a brief, classroombased MI intervention or an assessment control condition. At the end of the semester, MI group participants reported fewer drinks per occasion and fewer episodes of intoxication compared to controls. A classroom-based, MI-style intervention might be an efficient, sustainable, and effective means of reducing heavy drinking among college students.
\end{abstract}

Keywords: motivational interviewing, alcohol, college student, brief intervention

College student alcohol consumption is a significant public health problem (Ham \& Hope, 2003). Over $80 \%$ of college stu-

KuRT D. MichaEl earned his PhD in clinical psychology at Utah State University and completed his clinical internship at Duke University Medical Center. He is an associate professor of psychology at Appalachian State University (ASU) and associate director of clinical services at the ASU Institute for Health and Human Services. His primary area of research is psychotherapy outcome.

Lisa CurTin earned her PhD in clinical psychology at Virginia Polytechnic Institute and State University and completed her clinical internship at Brown University School of Medicine. She is an associate professor of psychology at Appalachian State University and associate director of research at the ASU Institute for Health and Human Services. Her primary area of research is in addictive behaviors.

DALE E. KIRKLEY earned his MA in human development and psychological counseling from Appalachian State University. He is coordinator of the Alcohol and Drug Assistance Program at ASU Counseling and Psychological Services Center. His primary research interest is in the area of motivational interviewing.

DAN L. JONES earned his $\mathrm{PhD}$ in counseling psychology at the University of Kansas. He is the director and chief psychologist of the ASU Counseling and Psychological Services Center. His area of research is college mental health issues.

RAFAel HARRIS JR. earned his PsyD in clinical psychology from Florida Institute of Technology in 1999. He is assistant director for clinical services and clinical assistant professor in the Counseling Center at the University of Florida and an affiliate professor in the Department of Counselor Education. His research interests are currently in the areas of substance abuse treatment, group counseling, and psychotherapy outcome.

THE ORDER OF THE FIRST AND SECOND AUTHORS was chosen at random. We wish to express our gratitude to the Freshman Seminar Program at ASU for collaborating with the clinical and research teams on this study. Further, we are thankful for the capable assistance of a cadre of students and colleagues, including Kim Pratt, Kendal McDevitt, Geri Miller, Diana Quealy-Berge, Garrett Hazelton, Laura Ritchie, Kate Tucker, Patrik Stridh, and Anna Coil. CORRESPONDENCE CONCERNING THIS ARTICLE should be addressed to Kurt D. Michael, Department of Psychology, Appalachian State University, 222 Joyce Lawrence Drive, Boone, NC 28608-2109. E-mail: michaelkd@appstate.edu dents report drinking alcohol (Johnston, O'Malley, Bachman, \& Schulenberg, 2004), and about $40 \%$ report a heavy drinking episode in the previous 2 weeks (O'Malley \& Johnston, 2002; Wechsler, Davenport, Dowdall, Moeykens, \& Castillo, 1994). Heavy episodic drinking (typically defined as at least four or five drinks in a single sitting) among college students is associated with poor academic performance, legal problems, risky sexual behaviors, and alcohol-related injuries and deaths (Hingson, Heeren, Zakocs, Kopstein, \& Wechsler, 2002; Perkins, 2002). Lowering the proportion of students engaging in heavy drinking is an objective of the surgeon general's national health promotion and disease prevention initiative (U.S. Department of Health and Human Services, 2000).

Alcohol prevention interventions on college campuses typically include traditional programs such as alcohol awareness weeks, wrecked car exhibits, and educational campaigns. Although easy to deliver, traditional primary prevention interventions are not often considered effective by college substance abuse prevention coordinators in changing alcohol consumption or reducing alcohol-related problems (Werch, Pappas, \& Castellon-Vogel, 1996), and broad-based drug prevention initiatives may relate to increased drinking (Werch \& Owen, 2002). Social norms campaigns have become a popular primary prevention strategy across the past 10 years. Social norms campaigns provide students with information via posters, public service announcements, advertisements, flyers, and pamphlets of survey results about college student drinking in a positive manner (e.g., the majority of students drink five or fewer drinks when they party), designed to challenge the perception that everyone in college drinks heavily. A number of uncontrolled longitudinal studies of social norm campaigns (e.g., Haines \& Spear, 1996) found decreases in the perception of campus heavy drinking and corresponding decreases in selfreported student drinking. However, some quasi-experimental investigations associated with social norm programs found decreased perceptions of peer drinking but no change in drinking behavior and some evidence of increased drinking (Clapp, Lange, Russell, Shillington, \& Voas, 2003). 
Brief motivational interventions are well supported in the alcohol treatment literature and show promise as interventions for college students. Brief assessment and feedback interventions for problem drinkers have moderately exceeded the effect of control conditions and have been nearly equal in effect to more extensive interventions (Bien, Miller, \& Tonnigan, 1993). Motivational interviewing (MI), a therapeutic style focused on the principles of expressing empathy, developing discrepancy, rolling with resistance, and supporting self-efficacy in order to increase intrinsic motivation to change and reduce ambivalence (Miller \& Rollnick, 2002), is frequently used in the context of brief interventions. Similarly, Burke, Arkowitz, and Menchola (2003) found that MI was equivalent to other active treatments and superior to no treatment and placebo controls, relative to reducing alcohol use in their meta-analytic review of MI.

Brief interventions and MI have been used in the context of secondary and tertiary prevention interventions with college students. Several studies have found that individual brief assessment and feedback interventions that used an MI style related to decreased drinking and drinking-related problems among heavydrinking college students compared with assessment-only control groups (Baer et al., 1992; Borsari \& Carey, 2000; Larimer, Cronce, Lee, \& Kilmer, 2001). Moreover, McNally and Palfai (2003) assigned freshman college students who endorsed a recent heavy drinking episode to one of two brief MI-style group discussion interventions (i.e., norm-based discrepancy discussion, actualself-ideal-self discrepancy discussion) or to an assessment-only control condition. The norm-based discrepancy discussion effects (i.e., personal drinking compared with normative drinking) exceeded the actual-ideal discrepancy discussion effects (i.e., personal current drinking vs. personal ideal drinking), and both active interventions exceeded the effects of the assessment alone on drinking behavior measured 4 weeks later.

Although brief motivational interventions are considered efficacious for college students, they have been tested with selected heavy drinkers only and almost exclusively in an individual format. College freshmen may represent a broad and diverse at-risk group. In general, first semester students and students living on campus are at greater risk for heavy drinking (Engs, Diebold, \& Hanson, 1996; Turrisi, Padilla, \& Wiersma, 2000) and adverse events such as academic underperformance and dropout than other cohorts (for further review, see Tobolowsky, Cox, \& Wagner, 2005). Several universities have freshman seminar programs (FSPs) designed to enhance the college experience, to increase retention, and to address potential pitfalls of college life before they become problematic. These programs are associated with higher retention and graduation rates, better psychological adjustment, improved academic performance, and increased student satisfaction (Barefoot, Warnock, Dickinson, Richardson, \& Roberts, 1999).

Focusing alcohol prevention efforts on students shortly after their arrival on campus makes good sense from empirical and prevention standpoints. Further, a group-based alcohol prevention intervention in an FSP class context has sustainable potential within a college environment. We delivered and tested a groupbased psychoeducational intervention using an MI style to freshmen participating in an FSP. The group-based intervention, described in detail below, used an MI style (Miller \& Rollnick, 2002), a decisional balance activity (Mann, 1972), and incorpo- rated a discussion of perceived college student drinking in relation to normative data. The present intervention differs from past brief interventions in format (group vs. individual), context (existing class vs. research group), and relation to participants (freshmen vs. identified heavy drinkers).

\section{Detailed Description of Group MI Prevention Intervention}

The brief group intervention (developed by Dale E. Kirkley and Rafael Harris Jr.) delivered in the present study used the MI counseling style (Miller \& Rollnick, 2002). The principles of MI style (nonlabeling and empathy-based style, creation of discrepancy, developing of confidence, rolling with resistance) were used throughout the group-based intervention. The spirit of MI is that it is a way of being with people that is collaborative rather than confrontational or authoritative. The counselor creates a welcoming, nonthreatening environment and a relationship that activates the student's capacity for beneficial change. Within the spirit of MI, students in the classes are approached in a respectful manner, without their instructor of record present, to accentuate the nonjudgmental, nonlabeling premise of MI that may elicit participant argument for change, known in MI as change talk (Miller \& Rollnick, 2002). Student experiences and perspectives are heard and not judged. Discussion and dialogue take on a partnership quality that is supportive and understanding and create an environment for change.

An important first step in the group brief intervention is to develop rapport with the students and seek to dissolve any resistance that students may harbor about addressing alcohol use. The facilitators give the students nothing to resist and simply start the process by "coming along beside them." Facilitators communicate to students that they are not judging students' alcohol use and have no intention of telling students what decisions they should make. The students' autonomy and self-efficacy are reinforced through acknowledging awareness that the students have reached a stage of independence and budding adulthood and are thus responsible for making many of their own decisions.

The process promoted through MI is supportive and collaborative but also evocative. The facilitator does not seek to provide information or insight to a passive student audience. In a traditional education and/or information-based classroom intervention program on alcohol issues, a facilitator might impart correct information and direct students on the actions and decisions to be healthy, safe, avoid negative consequences, and lower their risk for problem drinking. MI is based on the belief that the resources and motivation for change reside within the individual. The facilitators draw on the perceptions, values, and goals of the students to activate intrinsic motivation for change. The MI style respects the autonomy of the students and their capacity to choose from an informed perspective what is best for them. Change that is intrinsically motivated serves each student's own goals and values.

The central discussion activity for the brief group intervention is to examine the pros and cons of alcohol use from a student perspective with a decisional balance paradigm (Mann, 1972). In description, this activity sounds quite simple, yet it can be a very powerful tool for eliciting statements of desire, ability, reasons, and need for change from the students. Students are first asked to brainstorm and explore what they like, find enjoyable, or experience as perceived benefits from alcohol use. The facilitators re- 
spond to the input from the students nonjudgmentally and record this information on the board. Care is taken to patiently exhaust the various perspectives of the students and explore with them the nature of their collegiate drinking culture, weaving in humor and communicating understanding of what they experience without judgment. The facilitator responds to students reflectively in order to engage further conversation and gain clarity about their experiences and feelings. The students may use this portion of the activity to test the facilitator's reaction to their comments and attitudes about alcohol use, making neutrality and the use of reflection very important for the facilitators.

The facilitators then guide a process of having the students brainstorm and discuss the "not so good" things or cons about alcohol use. Again, care is taken to exhaust the "not so good" things concerning their thoughts about and experiences with alcohol use. Students are likely to engage actively and openly in this activity because they felt understood when expressing their positive thoughts about and experiences regarding alcohol use. This powerful and deceptively simple process of discussion sets the stage for a broad examination of the discrepancy that occurs in their culture of collegiate alcohol use. In MI, recognition of discrepancy between current behavior and personal goals and values can serve as a catalyst for change. Students are asked to reflect and comment on the discrepancies they have acknowledged between what they enjoy about alcohol use and the unpleasant or harmful consequences they may also experience. This nonthreatening way of having students actively discuss potential discrepancies between their current and desired behavior and outcomes is used to facilitate change talk. Skillful reflective listening, summaries, and exploratory open-ended questions are used to guide students in elaborating and expounding on change talk. Reflections can be complex, directive, skillful responses used to respond to resistance, to redirect the focus and meaning of a comment, or to increase elaboration of reasons, perceived ability, or commitment to change drinking behavior.

In MI, ambivalence is expected and can occur at any time during a change process. Although MI is often thought of as a nondirective intervention style, it is actually directive in its primary goal of aiding resolution of ambivalence (Miller \& Rollnick, 2002). Students may strongly think "two ways" about drinking. Facilitators respond to ambivalence reflectively, avoid argumentation, and guide a discussion of how students might seek to resolve their ambivalence. They may be asked, "How can you have the enjoyable, nonharmful aspects of alcohol use if you make the choice to drink, without experiencing these negative consequences?" The facilitators then guide the students in brainstorming and specifying means of achieving low-risk alcohol use. Facilitators also lead a discussion about the difficulties and challenges as well as the support and commitment the students may have for acting on their suggestions for resolving personal ambivalence related to alcohol use.

Throughout the group activity, a number of psychoeducational opportunities often present. For example, students may discuss concerns about or ask questions concerning issues of biological risk factors (e.g., family history, tolerance) and alcohol poisoning. These teachable moments are actively discussed with the nonlabeling MI spirit. Teaching moments are purposely brief and to the point, providing important risk reduction information, usually leading to an engaged discussion and eliciting further change talk.
These teachable moments are not lengthy enough to distract from the process or to create an expert perception of the facilitators.

An additional activity included in the brief intervention program is a limited but engaged discussion of perceptions of alcohol use among college students. College students tend to overestimate their peers' alcohol consumption (Perkins, Meilman, Leichliter, Cashin, \& Presley, 1999) and often believe their peers consume more alcohol than they themselves do (Borsari \& Carey, 2003). In addition, perceptions of normative college student drinking correlate positively with personal alcohol consumption (Perkins \& Wechsler, 1996). College student overestimation of peer drinking behavior may contribute to a heavy drinking environment by justifying heavy personal drinking behavior and/or guiding personal drinking behavior (e.g., perceived pressure to match normative drinking). Group facilitators seek student reaction to the discussion of campus and nationwide misperceptions of collegiate drinking. Facilitating a discussion regarding moderate use or abstinence can support the low-risk suggestions that have resulted from the decisional balance activity, providing an increased sense of normalcy to moderate, nonabusive drinking.

The group intervention culminated in a serious discussion in which the following question was asked: "What would it take, or what would have to happen to cause you to be concerned enough to make changes in your alcohol use?" This powerful question may personalize the issue of potential alcohol misuse so that the impetus for change is defined by the student, not the expert clinician. Asking students to consider this question can offer a very thought provoking zinger of change talk that may be well remembered by the students.

\section{The MI Study}

Beginning in 2003, three small controlled MI pilot trials have been implemented (fall 2003, spring 2004, fall 2004) within the context of a comprehensive southeastern university's FSP. Incoming freshman students enrolled into one of several FSP classrooms during registration. Each semester, a subset of FSP instructors were given a brief presentation describing the study and invited to allow the research team into their classrooms to discuss the project with their students. A research team member came to all participating classes and provided a brief presentation about the project to the FSP students and requested participation via an informed consent procedure. The freshman students who elected to participate in the study provided their informed consent and attended a pretreatment assessment session (outside of class) that took approximately $60 \mathrm{~min}$. The pretreatment assessments were conducted in a separate research facility, administered and monitored by graduate research assistants. The freshman students completed a demographics questionnaire, provided self-report data on drinking (i.e., 2-week Alcohol Time Line Follow-Back, Sobell, Sobell, Klajner, Pavan, \& Basian, 1986; self-reported number of drinking days during the past 30 days, number of intoxicating events during the past 30 days), alcohol-related problems during the past 30 days (Rutgers Alcohol Problem Index; White \& Labouvie, 1989), psychopathology (Symptom Checklist 90-Revised; Derogatis, 1994), and the Big Five personality traits (International Personality Item Pool; Goldberg, 1999). Students who completed the assessment were paid $\$ 10$ for their time. 
Across the three trials, a total of 91 freshmen ( 34 men, 57 women) participated in the study. The sample was $93.7 \%$ Caucasian, 4.3\% African American, 1\% Hispanic, and 1\% Asian American. The FSP classroom was assigned randomly as either an assessment control classroom $(N=7)$ or an MI group prevention classroom $(N=7)$. Of the 91 freshmen who took part in the project, 44 were from control classrooms and 47 were from MI group prevention classrooms. At pretreatment evaluation, the groups did not differ significantly on age, $t(89)=-1.63, p=.11$; sex, $\chi^{2}(1, N=91)=1.12, p=.29$; age at first alcohol use, $t(76)=$ $1.51, p=.12$; number of drinking days during the past 30 days, $t(89)=0.53 ; p=.60$; number of drinks consumed during the past 14 days, $t(89)=0.14, p=.89$; number of times drinking to intoxication during the past 30 days, $t(89)=1.51, p=.73$; and alcohol-related problems during the past 30 days, $t(89)=$ $-1.05, p=.30$. Within each group, the percentage of freshmen who did not report any drinking during either the pre- or posttreatment assessments was roughly equivalent (18.2\% for control; $17.0 \%$ for MI). The preintervention descriptive data are summarized in Table 1.

After the preintervention assessment, the FSP students assigned to MI classrooms took part in an MI-style psychoeducational intervention. The MI facilitators were experienced therapists with considerable MI training (two master's-level counselors, one doctoral-level psychologist; mean years of experience $=12$ ) and two of the therapists were formally trained to use the MI style by Miller and associates. The intervention was not manualized, and evidence suggests lower effect sizes for manualized MI interventions compared with nonmanualized MI interventions (Hettema, Steele, \& Miller, 2005). In fall 2003 and spring 2004, the sessions were $50 \mathrm{~min}$ in duration (100 min total; approximately 2 weeks apart); whereas in fall 2004, one session (75 min in duration) was conducted. The students enrolled in the control classrooms participated in only the assessment sessions.

At posttreatment, all participants were contacted for follow-up assessment that took place between 30 and 45 days after the MI intervention. The posttreatment assessments were conducted outside the classroom setting in a separate research facility, administered and monitored by graduate research assistants. Longitudinal assessments (2-2.5 years after the pretreatment evaluation) are planned (spring 2006) but have yet to be conducted.

Table 1

Descriptive Statistics by Group at Pretreatment

\begin{tabular}{|c|c|c|c|c|}
\hline \multirow[b]{2}{*}{ Variable } & \multicolumn{2}{|c|}{$\begin{array}{c}\text { Control } \\
(n=44)\end{array}$} & \multicolumn{2}{|c|}{$\begin{array}{c}\text { Experimental } \\
\quad(n=47)\end{array}$} \\
\hline & $M$ & $S D$ & $M$ & $S D$ \\
\hline Age (years) & 18.2 & 0.7 & 18.5 & 0.9 \\
\hline Age of first use (years) & 15.4 & 1.7 & 14.7 & 2.2 \\
\hline Drinking days (past 30 days) & 5.9 & 6.1 & 5.3 & 5.8 \\
\hline TLFB (past 14 days) & 15.9 & 23.7 & 16.5 & 19.3 \\
\hline Intoxicating events (past 30 days) & 4.4 & 5.1 & 4.1 & 5.2 \\
\hline Mean RAPI score & 5.4 & 6.1 & 6.7 & 6.0 \\
\hline
\end{tabular}

Note. $\quad$ TLFB $=$ Time Line Follow-Back; RAPI $=$ Rutgers Alcohol Problem Index.

\section{Postintervention Outcomes}

As reported in Table 2, the average number of drinking days during the past 30 days was virtually unchanged across both groups (effect size $=0.09$ ). In addition, self-reported alcohol problems did not change differentially across groups (effect size $=$ $-0.09)$. However, students in the MI group consumed an average of 4.5 fewer drinks during the previous 14 days at postintervention, compared with the control group students (effect size $=0.19$ ). Moreover, the MI participants reported an average of 1.5 fewer episodes of intoxication during the previous 30 days at postassessment, compared with the control group participants (effect size $=$ 0.34). Thus, although both groups drank about as frequently after the intervention, on average the MI participants consumed fewer drinks and became intoxicated less often than the control group participants. These data are summarized in Table 2.

\section{Clinical Implications and Applications}

The findings from this study suggest that a brief group intervention that used an MI style, decisional balance exercise, and norm-based discussion was reasonably effective at reducing selfreported drinking quantity and episodes of intoxication for those who participated in the prevention intervention. A previous comparison of alcohol-using college students randomly assigned to an assessment control, written decisional balance, or individual inperson decision balance exercise did not result in differences between conditions on 2-week drinking outcomes (Collins \& Carey, 2005), suggesting the current findings exceed the effects of the decisional balance activity alone and that the MI style is an integral component of the intervention. The only other groupbased MI intervention for college students compared two discrepancy producing discussions and selected for heavy drinkers (McNally \& Palfai, 2003). Our intervention also involved an MI style and norm-based discussion; however, the main discussion revolved around the decisional balance exercise, and we did not select for heavy drinkers.

The current intervention was delivered in the context of an FSP already associated with student benefits (Barefoot et al., 1999). Thus, the assessment-only control condition served as a relatively conservative control. Although the magnitude and scope of the effects are modest at best, perhaps the most compelling finding is the reduction of the average number of intoxicating events each month by approximately 1.5 episodes. Moreover, this effect was achieved with a relatively small dosage (75-100 min) of prevention intervention that was delivered in the context of an existing classroom (group) context. The effects of the current intervention have practical implications within a typical college setting, as the intervention can be delivered in a relatively efficient and costeffective way.

In future studies of this type, it will be important to examine whether a higher dosage of MI might lead to more substantial changes in drinking behavior and the associated consequences among college students. For example, provision of individualized feedback based on assessment information might be a relatively efficient way to increase the intensity of the current group-based intervention. In addition, it will be important to assess effects across time, given potential for diminishing effects (Hettema et al., 2005). Although the majority of brief intervention studies with 
Table 2

\section{Posttreatment Outcomes}

\begin{tabular}{|c|c|c|c|c|}
\hline \multirow[b]{2}{*}{ Variable } & \multicolumn{2}{|c|}{$\begin{array}{l}\text { Control } \\
(n=44)\end{array}$} & \multicolumn{2}{|c|}{$\begin{array}{l}\text { Experimental } \\
\quad(n=47)\end{array}$} \\
\hline & $M$ & $S D$ & $M$ & $S D$ \\
\hline Drinking days (past 30 days) & 5.8 & 5.5 & 5.3 & 4.7 \\
\hline TLFB (past 14 days) & 18.1 & 29.4 & 13.6 & 16.7 \\
\hline Intoxicating events (past 30 days) & 4.2 & 5.3 & 2.7 & 3.2 \\
\hline Mean RAPI score & 4.6 & 5.9 & 5.1 & 5.7 \\
\hline
\end{tabular}

Note. $\quad$ TLFB $=$ Time Line Follow-Back; RAPI $=$ Rutgers Alcohol Problem Index.

college students assess short-term outcomes (Larimer et al., 2001), there is some evidence of 4-year maintenance effects (Baer et al., 1992). We plan to continue to follow our sample to assess maintenance effects. Finally, although intervention providers were experienced MI therapists we did not use an independent manipulation check of intervention integrity.

In summary, on the basis of the results of this study, psychologists and other professionals working with college students may want to consider the addition of an MI style to their outreach services, although the long-term effects of this intervention have yet to be assessed. This study showed that even a short-term prevention intervention effectively reduced quantity of alcohol consumption among college freshmen. Further, such a program could be readily integrated and sustained into the college curriculum with existing campus resources although institutional support for classroom infusion will likely be necessary.

\section{References}

Baer, J. S., Marlatt, G. A., Kivlahan, D. R., Fromme, K., Larimer, M. E., \& Williams, E. (1992). An experimental test of three methods of alcohol risk reduction with young adults. Journal of Consulting and Clinical Psychology, 60, 974-979.

Barefoot, B. O., Warnock, C. L., Dickinson, M. T., Richardson, S. E., \& Roberts, M. R. (Eds.). (1999). Exploring the evidence: Volume 2. Reporting outcomes of first-year seminars. Columbia, SC: University of South Carolina, National Resource Center for the First-Year Experience and Students in Transition.

Bien, T. H., Miller, W. R., \& Tonnigan, J. S. (1993). Motivational interviewing with alcohol outpatients. Behavioural and Cognitive Psychotherapy, 23, 347-356.

Borsari, B., \& Carey, K. B. (2000). Effects of a brief motivational intervention with college student drinkers. Journal of Consulting and Clinical Psychology, 68, 728-733.

Borsari, B., \& Carey, K. B. (2003). Descriptive and injunctive norms in college drinking: A meta-analytic integration. Journal of Studies on Alcohol, 64, 331-341.

Burke, B. L., Arkowitz, H., \& Menchola, M. (2003). The efficacy of motivational interviewing: A meta-analysis of controlled clinical trials. Journal of Consulting and Clinical Psychology, 71, 843-861.

Clapp, J. D., Lange, J. E., Russell, C., Shillington, A., \& Voas, R. B. (2003). A failed norms social marketing campaign. Journal of Studies on Alcohol, 64, 409-414.

Collins, S. E., \& Carey, K. B. (2005). Lack of effect for decisional balance as a brief motivational intervention for at-risk college drinkers. Addictive Behaviors, 7, 1425-1430.

Derogatis, L. R. (1994). SCL-90-R: Administration, scoring, and procedures manual (3rd ed.). Minneapolis, MN: NCS Pearson.
Engs, R. C., Diebold, B. A., \& Hanson, D. J. (1996). The drinking patterns and problems of a national sample of college students, 1994. Journal of Alcohol and Drug Education, 41, 13-34.

Goldberg, L. R. (1999). A broad-bandwidth, public domain, personality inventory measuring the lower-level facets of several five-factor models. In I. Mervielde, I. Deary, F. De Fruyt, \& F. Ostendorf (Eds.), Personality psychology in Europe (Vol. 7, pp. 7-28). Tilburg, The Netherlands: Tilburg University Press.

Haines, M., \& Spear, S. (1996). Changing the perception of the norm: A strategy to decrease binge drinking among college students. Journal of American College Health, 45, 134-140.

Ham, L. S., \& Hope, D. A. (2003). College students and problematic drinking: A review of the literature. Clinical Psychology Review, 23, 719-759.

Hettema, J., Steele, J., \& Miller, W. R. (2005). Motivational interviewing. Annual Review of Clinical Psychology, 1, 91-111.

Hingson, R. W., Heeren, T., Zakocs, R. C., Kopstein, A., \& Wechsler, H. (2002). Magnitude of alcohol-related mortality and morbidity among U.S. college students ages 18-24. Journal of Studies on Alcohol, 63, $136-144$.

Johnston, L. D., O’Malley, P. M., Bachman, J. G., \& Schulenberg, J. E. (2004). Monitoring the Future national survey results on drug use, 1975-2003. Vol. 2: College students and adults ages 19-45 (NIH Publication No. 04-5508). Bethesda, MD: National Institute on Drug Abuse.

Larimer, M. E., Cronce, J. M., Lee, C. M., \& Kilmer, J. R. (2001). Brief interventions in college settings. Alcohol Research \& Health, 28, $94-$ 104.

Mann, L. (1972). Use of a "balance-sheet" procedure to improve the quality of personal decision making: A field experiment with college applicants. Journal of Vocational Behavior, 2, 291-300.

McNally, A. M., \& Palfai, T. P. (2003). Brief group alcohol interventions with college students: Examining motivational components. Journal of Drug Education, 33, 159-176.

Miller, W. R., \& Rollnick, S. (2002). Motivational interviewing: Preparing people for change (2nd ed.). New York: Guilford Press.

O'Malley, P. M., \& Johnston, L. D. (2002). Epidemiology of alcohol and other drug use among American college students. Journal of Studies on Alcohol, 63(Suppl. 14), 23-39.

Perkins, H. W. (2002). Surveying the damage: A review of research on consequences of alcohol misuse in college populations. Journal of Studies on Alcohol, 63(Suppl. 14), 91-100.

Perkins, H. W., Meilman, P. W., Leichliter, J. S., Cashin, J. R., \& Presley, C. A. (1999). Misperceptions of the norms for the frequency of alcohol and other drug use on college campuses. Journal of American College Health, 47, 253-258.

Perkins, H. W., \& Wechsler, H. (1996). Variation in perceived college drinking norms and its impact on alcohol abuse: A nationwide study. Journal of Drug Issues, 26, 961-974.

Sobell, M. B., Sobell, L. C., Klajner, F., Pavan, D., \& Basian, E. (1986). The reliability of a timeline method for assessing normal drinker college students' recent drinker history: Utility for alcohol research. Addictive Behavior, 11, 149-161.

Tobolowsky, B. F., Cox, B. E., \& Wagner, M. T. (Eds.). (2005). Exploring the evidence: Reporting research on first-year seminars (Vol. 3, Monograph No. 42). Columbia, SC: University of South Carolina, National Resource Center for the First-Year Experience and Students in Transition.

Turrisi, R., Padilla, K. K., \& Wiersma, K. A. (2000). College student drinking: An examination of theoretical models of drinking tendencies in freshmen and upperclassmen. Journal of Studies on Alcohol, 61, 598602 .

U.S. Department of Health and Human Services (2000). Healthy people 2010: The cornerstone for prevention. Rockville, MD: Author. 
Wechsler, H., Davenport, A., Dowdall, G., Moeykens, B., \& Castillo, S. (1994). Health and behavioral consequences of binge drinking in college: A national survey. Journal of the American Medical Association, 272, 1672-1677.

Werch, C. E., \& Owen, D. M. (2002). Iatrogenic effects of alcohol and drug prevention programs. Journal of Studies on Alcohol, 63, 581-590.

Werch, C. E., Pappas, D. M., \& Castellon-Vogel, E. A. (1996). Drug use and prevention efforts at colleges and universities in the United States. Substance Use and Misuse, 31, 65-80.
White, H. R., \& Labouvie, E. W. (1989). Towards the assessment of adolescent problem drinking. Journal of Studies on Alcohol, 50, $30-37$.

Received November 10, 2005

Revision received March 27, 2006

Accepted May 1, 2006

\section{Members of Underrepresented Groups: Reviewers for Journal Manuscripts Wanted}

If you are interested in reviewing manuscripts for APA journals, the APA Publications and Communications Board would like to invite your participation. Manuscript reviewers are vital to the publications process. As a reviewer, you would gain valuable experience in publishing. The P\&C Board is particularly interested in encouraging members of underrepresented groups to participate more in this process.

If you are interested in reviewing manuscripts, please write to the address below. Please note the following important points:

- To be selected as a reviewer, you must have published articles in peer-reviewed journals. The experience of publishing provides a reviewer with the basis for preparing a thorough, objective review.

- To be selected, it is critical to be a regular reader of the five to six empirical journals that are most central to the area or journal for which you would like to review. Current knowledge of recently published research provides a reviewer with the knowledge base to evaluate a new submission within the context of existing research.

- To select the appropriate reviewers for each manuscript, the editor needs detailed information. Please include with your letter your vita. In the letter, please identify which APA journal(s) you are interested in, and describe your area of expertise. Be as specific as possible. For example, "social psychology" is not sufficient-you would need to specify "social cognition" or "attitude change" as well.

- Reviewing a manuscript takes time (1-4 hours per manuscript reviewed). If you are selected to review a manuscript, be prepared to invest the necessary time to evaluate the manuscript thoroughly.

Write to Journals Office, American Psychological Association, 750 First Street, NE, Washington, DC 20002-4242. 